\title{
Validation of the Mobility Nursing Outcome in Stroke Survivors
}

\author{
Rafaella Pessoa Moreira, PhD, Thelma Leite de Araujo, PhD, Tahissa Frota Cavalcante, PhD, \\ Nirla Gomes Guedes, PhD, Alice Gabrielle de Sousa Costa, MSN, and Marcos Venicios de Oliveira Lopes, PhD
}

Rafaella Pessoa Moreira, PhD, is a Professor of the Department of Nursing, University of International Integration of African-Brazilian Lusophone, Redenção, Ceará, Brazil; Thelma Leite de Araujo, PhD, is a Professor of the Department of Nursing, Federal University of Ceará, Ceará, Fortaleza, Brazil; Tahissa Frota Cavalcante, PhD, is a Professor of the Regional University of Cariri, Ceará, Brazil; Nirla Gomes Guedes, PhD, is a Professor of the Integrated College of Ceará, Fortaleza, Ceará, Brazil; Alice Gabrielle de Sousa Costa, MSN, is a PhD student of the Federal University of Ceará, Ceará, Fortaleza, Brazil and a Visiting Scholar in the College of Nursing, The University of lowa, lowa City, lowa; and Marcos Venicios de Oliveira Lopes, PhD, is a Professor of the Department of Nursing, Federal University of Ceará, Ceará, Fortaleza, Brazil.

\section{Search terms:}

Mobility limitation, nursing

outcome, stroke, validation study

\section{Author contact:}

rafaellapessoa@hotmail.com, with a copy to the Editor:

journal@nanda.org

This research was supported by a grant from National Council for Scientific and Technological Development (CNPq).
PURPOSE: To validate the indicators of the mobility nursing outcome.

METHODS: This is a methodological study carried out from February to April 2011. The instrument was assessed by 23 nurses, and the data were analyzed using SPSS version 16.0.

FINDINGS: The title "physical mobility" was the most suitable. There was a statistical proportion of less than $85 \%$ of experts who agreed that the indicators running, crawling, jumping, and moves with ease were relevant to mobility nursing outcome $(p<.05)$. However, these indicators were not associated with stroke patients.

CONCLUSIONS: For stroke patients, some indicators are not adequate to their evaluation.

IMPLICATIONS FOR NURSING PRACTICE: This work supports the tools' development to assess accurate outcome measurements in specific populations.

OBJETIVO: Validar os indicadores dos resultados de enfermagem obilidade.

MÉTODOS: Este é um estudo metodológico realizado de fevereiro a abril de 2011. $O$ instrumento foi avaliado por 23 enfermeiras, e os dados foram analisados usando SPSS versão 16.0.

DADOS: O título de "mobilidade física", foi o mais adequado. Houve uma proporção estatística inferior a $85 \%$ dos especialistas que concordaram que os indicadores corre, rastejar, pular, e se move com facilidade eram relevantes para a o resultado de enfermagem Mobilidade $(p<0.05)$. No entanto, estes indicadores não foram associados com os pacientes com acidente vascular cerebral.

CONCLUSÕES: Para pacientes com AVC, alguns indicadores não são adequados para a suaavaliação.

IMPLICAÇõES PARA A PRÁTICA DE ENFERMAGEM: 0 presente trabalho apóia o desenvolvimento das ferramentaspara avaliar as medições de resultados precisos em populações específicas.
The evaluation of nursing outcomes is a process that involves deciding the best outcome indicators to be used, and the best way and frequency that they can be quantified (Moorhead, Johnson, Mass, \& Swanson, 2012). Additionally, different populations have specific needs that should be contemplated in nursing taxonomies. For instance, people with stroke, which is one of the most serious cerebrovascular diseases, usually present serious physical and cognitive problems. So it is an important issue that must be considered in the scope of nursing care due to the possibility of high level of physical dependency and the financial cost for health services (Diederichs et al., 2011).

Thereby, the mobility nursing outcome proposed by the Nursing Outcomes Classification (NOC) (Moorhead et al., 2012) is the most adequate to evaluate specific interventions to the diagnosis of impaired physical mobility in that it is significant in people with stroke because of its high potential of physical sequelae.

Plus, nurses incorporating NOC standardized outcomes in their practice are able to quantify the change in patient 
status after interventions, and to monitor progress. However, NOC does not include all outcomes or indicators that might be important for nursing (Moorhead et al., 2012), and the understanding and measurement of these indicators can change by country or region, especially for nurses who do not have most of their interventions or results oriented by protocols. Given the diversity of definitions of the term mobility and the importance of continuously upgrading nursing classifications, it is important to develop validation studies in order to clarify the concepts and to enable more efficient nursing work. Content validation is an option that is recommended to confirm the indicators proposed and recommended by experts (Gurková, Žiaková, \& Cáp, 2011).

The purpose of this research was to validate the indicators of the mobility nursing outcome proposed by the NOC (Moorhead et al., 2012), verifying with experts the adequacy of these indicators. Constitutive and operational definitions built through a literature review were established in order to reach a uniform understanding of each indicator by the experts.

\section{Methodology}

This is a methodological study carried out from February to April 2011. It was based on psychometric criteria established by Pasquali (1999) in order to provide the measurement of the concept adequacy and the level to which the outcome measures exactly what it is supposed to measure. Seven psychometric criteria were used: behavioral (the item should correspond to a clear action capable of being performed by the population), simplicity (the item should express a unique idea), clearness (the item should be short, simple, and understandable), relevance (the item should be consistent), precision (the item should be distinct from the others), typicality (the item should be harmonic with its attributes), and amplitude (the item should cover all the phenomenon aspects).

\section{Sample}

The experts were nurses who were selected using the adapted Fehring's criteria (Fehring, 1994): master's degree (2 points), research with publication (2 points), published article (3 points), doctorate degree (4 points), at least 1 year of clinical practice (1 point), and specialization degree (2 points). The criteria applied should be related to the nursing taxonomies. In addition, nurses should have at least a master's degree and get a minimum score of 5 points to participate as experts in the study.

Regarding sample size, the following formula was applied: $n=Z_{\alpha}{ }^{2} \times P \times(1-P) / d^{2}$, in which $Z_{\alpha}$ refers to the confidence level (a $95 \%$ confidence level was adopted), $P$ is the acceptable proportion of experts who agree with the relevance of the nursing outcome component (a minimum proportion of $85 \%$ was considered acceptable), and $d$ is the extension to the confidence interval of an acceptable proportion (15\%). The final calculation was defined by $n=1.96^{2}$ $\times 0.85 \times 0.15 / 0.15^{2}$, which results in 22 experts. Thereby, 55 experts were invited, and 23 answered the request and agreed to participate.

\section{Instrument}

A previous literature review study (Moreira, 2011) built the constitutive and operational definitions of the mobility outcome title, definition, and indicators. The data collection instrument was organized in three parts. The first part was the instructions to complete the instrument. The second part was about the experts' profile. The third part corresponded to the psychometric criteria applied to verify the adequacy of the indicators, and the expert could choose the most suitable title and definition of the outcome. In addition, every part of the instrument had blank spaces in which experts could give suggestions to change the indicator in any way or even to add a new one, if deemed necessary.

\section{Procedure}

Participation in this study was voluntary and occurred through e-mail. The study was approved by a research ethics committee, and the participants provided written consent to join the study. Then, the instrument was sent to those who agreed. The experts evaluated the title, and the constitutive and operational definitions, from each indicator based on seven psychometric criteria proposed by Pasquali. For each criterion, a number was chosen according to the following options: -1 (criteria not satisfied, or title/ constitutive definition/operational definition are not suitable); 0 (indecision related to the criteria suitability, or title/ constitutive definition/operational definition are somehow suitable); or +1 (criteria satisfied, or title/constitutive definition/operational definition are suitable). In the end, the expert could suggest the addition or removal of some indicator if deemed pertinent.

The data were compiled in a sheet of Microsoft Office Excel 2007 software and were analyzed by the SPSS 19.0 software. To evaluate the suitability of psychometric criteria relative to each definition/magnitude operational set, averages for each one of those criteria were calculated. The averages were the division between the sum of all indicator scores and the number of experts. Then, a binomial test was used to examine the proportion of experts who indicated as suitable criteria those higher or equal to $85 \%$ against the alternative hypothesis, in which the proportion was less than $85 \%$. A $p$ value $<.05$ was taken to indicate statistical significance for this procedure. Afterward, the statistical analysis and the suggestions from the experts about the indicators of the outcome were considered to establish the best indicators related to patients after stroke. 


\section{Findings}

Most experts were female (95.7\%) and work in governmental universities and hospitals (73.9\%). The average age was $35.3( \pm 9.9)$ years, and they graduated in an average of $12.6( \pm 10.1)$ years. The majority got a master's degree (78.3\%) and have developed research about nursing outcomes (52.2\%) and mobility or stroke (73.9\%). In general, they had more practical experience (95.2\%) with the subject than academics, and most of them have been using nursing terminology in clinical practice.

About the concept analysis, two different titles of the mobility outcome were sent to the experts. One of them was from the NOC, Mobility (Moorhead et al., 2012), and the other title was a result of the concept analysis, Physical Mobility, and this term was judged as the most suitable by $82.6 \%$ of the experts.

In addition, two mobility concepts were submitted for analysis. The first is the NOC concept: ability to move purposefully in own environment independently, with or without assistance device (Moorhead et al., 2012). The other concept was identified and elaborated in the study: ability of the person to move from a postural position to another, or from one place to another, independently, with or without an assistance device, such as a cane. The concept built draws on the study analysis, and it was considered the most suitable by $69.5 \%$ of the experts. Afterward, they suggested removing the words as a cane. Plus, $37.5 \%$ of the experts who chose the NOC concept proposed changes. As a result, this study proposes the replacement of the current mobility outcome definition to the "ability of the person to move from a postural position to another or from a place to another, independently, with or without assistance device."

In Table 1, it is possible to verify the binomial test relative to title, constitutive definition, and operational definition for each indicator considering the psychometric criteria: behavioral, clearness, relevance, precision, typicality, and amplitude. Thus, the indicators balance, coordination, gait, joint movement, transfer performance, and walking presented statistical proportion of $85 \%$ for titles $(p>.05)$. Nevertheless, we found a statistical proportion-less than 85\%-of experts who agreed with the relevance of the indicators running, crawling, and jumping to the mobility nursing outcome $(p<.05)$.

Additionally, a statistical proportion of less than $85 \%$ of the experts who agreed with the item adequacy was realized in the following indicators: muscle movement $(p=.046$ for simplicity and $p=.046$ for typicality), body positioning performance $(p=.046$ for behavioral and $p=.046$ for precision), and moves with ease in all the criteria. Moreover, the indicators balance, muscle movement, joint movement, transfer performance, and crawling showed a statistical proportion of $85 \%$ for constitutive definitions $(p>.05)$ according to the experts' analysis. We found a proportion of less than $85 \%$ of experts who evaluated the indicators running and jumping as relevant to the outcome $(p<.05)$.
On the other hand, a statistical proportion less than $85 \%$ of agreement was noticed for the indicators coordination $(p<.002$ for simplicity, $p<.003$ for clearness, and $p<.001$ for typicality), gait ( $p=.046$ for amplitude), body positioning performance ( $p=.046$ for behavioral and $p=.046$ for precision), running and jumping ( $p=.046$ for relevance), walking ( $p=.046$ for simplicity, $p<.006$ for clearness), and moves with ease in all the criteria evaluated.

According to the experts' analysis, the indicator coordination showed statistical proportion of $85 \%$ for the operational definitions of the indicators $(p>.05)$. A statistical proportion less than $85 \%$ of experts agreed with the relevance of the indicators jumping and body positioning performance to the mobility nursing outcome $(p<.05)$. Plus, the same proportion less than $85 \%$ was realized for the indicators balance ( $p<.003$ for clearness), gait ( $p=.046$ for simplicity, $p=.015$ for clearness, $p=.046$ for precision, and $p=.015$ for amplitude), muscle movement ( $p=.015$ for clearness and $p=.046$ for precision), joint movement ( $p=$ .015 for clearness), body positioning performance $(p<.006$ for clearness, $p<.002$ for relevance, and $p<.003$ for amplitude), transfer performance ( $p<.001$ for precision), walking ( $p=.046$ for precision), crawling ( $p=.015$ for simplicity, $p=.046$ for clearness, $p=.046$ for precision, and $p=.046$ for typicality), and moves with ease $(p<.002$ for clearness, $p=.015$ for precision, $p=.046$ for typicality, and $p=.015$ for amplitude).

Some experts suggested changes in the titles, constitutive definitions, or operational definitions in the cases in which the psychometric criteria were considered in some way unsuitable. Moreover, additional indicators were suggested: feeding, bathing/dressing, fine motor coordination, upper extremity movement, and cognition. However, these were judged as impertinent by the authors, and the indicators were not included.

The more suitable indicators were balance, coordination, gait, walking, muscle movement, joint movement, body positioning performance, and transfer performance. The addition of any other indicator is not suggested. However, the indicators running, jumping, and crawling presented by NOC were considered unsuitable in the nursing care process of a patient with stroke. Furthermore, the experts recommended disregarding the indicator moves with ease because this one is already considered in other indicators. Nevertheless, it is worth highlighting the fact that those indicators might be important in the evaluation of a population with other kinds of chronic disease, which require other validating studies.

\section{Discussion}

The choice of nurses who are experts is one of the most difficult aspects in current validation studies of nursing taxonomies when considering the criteria of Fehring (Chaves, Carvalho, \& Rossi, 2008). At the same time, the nursing taxonomies do not refer their own criteria to select the experts. Thus, many researchers have used a variety of 
Table 1. Adherence of Titles, Constitutive Definitions, and Operational Definitions of the Indicators in Relation to Behavioral, Simplicity, Clearness, Relevance, Precision, Typicality, and Amplitude Criteria

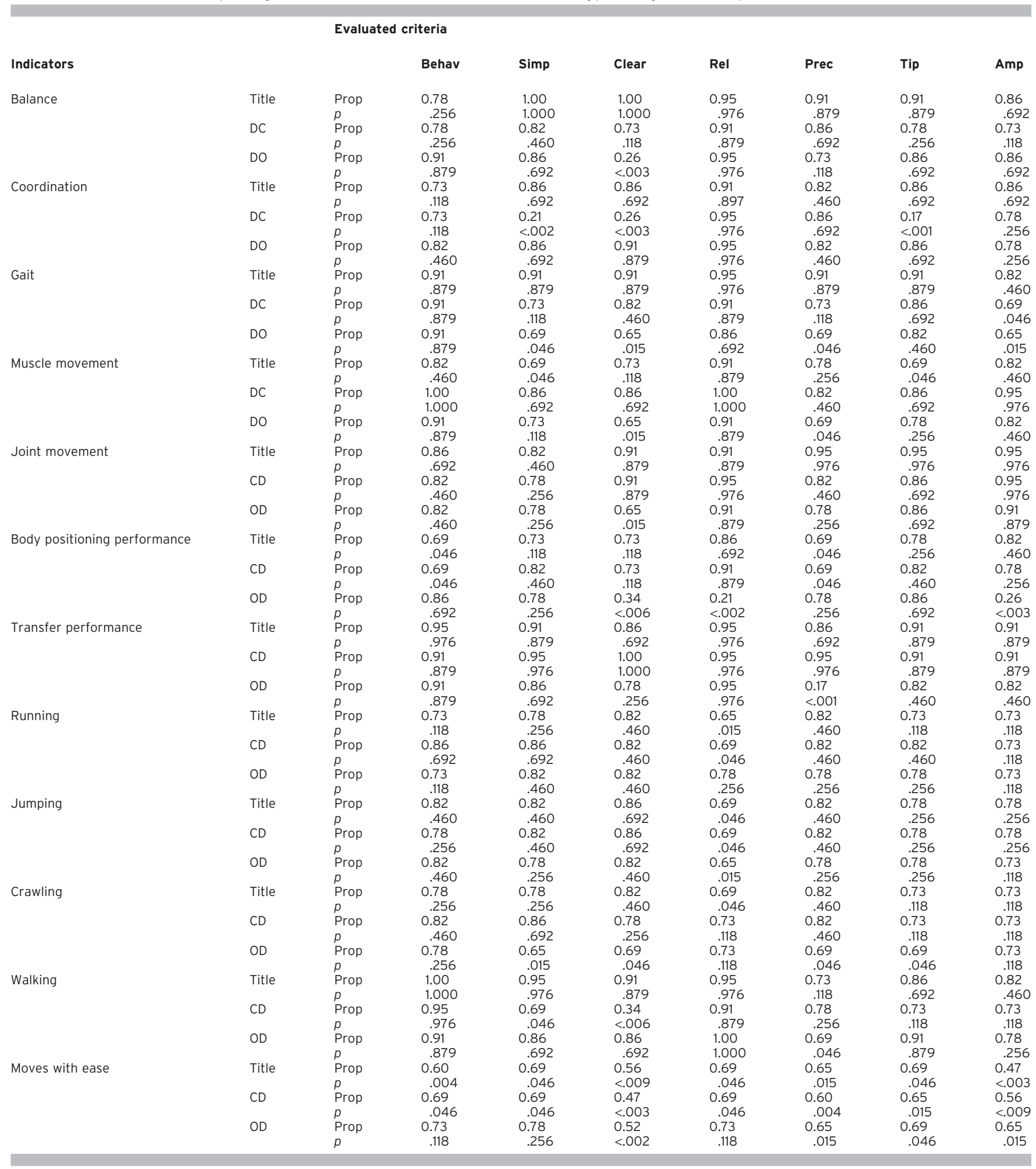

Behav, behavioral; Simp, simplicity; Clear, clearness; Rel, relevance; Prec, precision; Tip, typicality; Amp, amplitude; Prop, observed proportion; $p$, $p$ value; CD, constitutive definitions; OD, operational definitions. 
different criteria to establish a sample; however, the adoption of unsuitable criteria can contribute to unreliable data (Galdeano \& Rossi, 2006).

The profile of experts in this study was similar to that of another study that identified most experts as female, graduated, with experience in the area, and who had learned about nursing taxonomies through continuing education in hospital settings and nursing associations (Gurková et al., 2011). Most of them were working in universities and participating in research groups about systematization of nursing care. In addition, the nursing process has been used mostly in clinical nursing practice (Vitor, 2010).

In this study, the experts who analyzed the mobility outcome title chose the title that was suggested by the study instead of the current title from NOC. Physical mobility is the most suitable title, as it comes from a thorough literature search. The word mobility was considered too broad and can be used in other contexts not concerning people. There are different terminologies related to mobility in the health science field's descriptors as well. Those aspects support the changing of the current mobility outcome denomination to physical mobility in order to become more specific about the evaluation of the indicators related to a person's physical mobility. Furthermore, the outcome is related to the nursing diagnosis impaired physical mobility from NANDA-I (Herdman, 2012).

The psychometrical criteria of clearness and precision were those that showed less statistical associations compared with the others. This implies the need to change the nomenclature of the indicators. The suggestions of the experts were very important in order to understand how the nomenclature could be improved. The changes were made in order to make the item clear and to make the measurement more precise. Thus, it was possible to evaluate the titles in a definitive way after the empirical data collection about the item, as proposed by Pasquali (1999).

The indicators considered suitable to the mobility outcome by the experts were balance, coordination, gait, walking, muscle movement, joint movement, body positioning performance, and transfer performance. These indicators were considered in a stroke patient context, and according to the nurses they could be related to the demand of that population in order to make the instrument more targeted to them, as well as to health institutions responsible for their care delivery.

In general, the aspects of physical mobility are interrelated and involved in rehabilitation of daily activities, independence, functional mobility, and prevention of falls (Tyson, Connell, Busse, \& Lennon, 2009). However, the indicators running, jumping, crawling, and moves with ease from the NOC were not related to the main goal in health rehabilitation of a patient after stroke. That fact is supported by clinical practice experience, teaching, and research developed by the experts. In a literature revision study about mobility outcome, no publications showed those indicators as important actions expected in that specific population (Moreira, 2011).
According to the experts, stroke patients are physically unable to perform complex movements as running and jumping due to the clinical situation of mobility problems that arise with a stroke event. Plus, these complex movements are not stroke patients' priority, as the main goal should be to improve residual mobility. Usually, people after stroke have poor mobility and low levels of physical activity. Even though exercise programs to improve walking capacity and fast walking can be encouraged, many patients present such seriously impaired mobility that some interventions and actions can even increase the risk of complications, such as falls (Dean et al., 2012).

Thus, the indicators that demand a high level of physical performance can be disregarded. Avoiding those actions is important because they could be dangerous. Nurses ask patients with such considerable movement limitations not to do actions that require much physical effort. As nurses review the outcomes, current indicators may require modification, and other outcomes will be identified. Therefore, we expect that the classification will be continually evolving, reflecting changes in nursing practice and healthcare delivery (Moorhead et al., 2012).

A limitation of this study, however, can be the fact that there is not a uniform way to choose the participants in validation studies, and this might negatively influence the process of validation since some experts did not contribute with significant suggestions even though they met the Fehring's criteria. In addition, the study that was done focused on a specific population. So the exclusion of indicators suggested by the experts cannot be generalized since these indicators can be applied in other populations.

\section{Conclusion}

The changes suggested by experts were related to the population characteristics and were aimed to clarify understanding by nurses. It is not useful to investigate items that are not relevant for clinical evaluation of people after stroke, who usually lose the basic ability to move, or items that are secondary to other items that include the same idea. Thus, this study verified that the current mobility nursing outcome proposed by the NOC is not completely suitable for people who present impaired mobility after stroke. The indicators presented differences, and some of them were not found in the literature review and concept analysis as important items to be measured. According to the experts, they were not indicated as a target for patients after stroke.

As implications for nursing practice, this study can lead to the improvement of NOC to assess accurate outcome measurements in specific populations. Plus, it can contribute toward clarifying the concept, and lead nurses to a uniform understanding about the results and the plan of care that they can establish, even though they do not have protocols to orient their practice. Thus, more validation studies of the mobility outcome with different populations 
in order to formulate the most complete concept and efficient indicators are indicated.

\section{References}

Chaves, E. C. L., Carvalho, E. C., \& Rossi, L. A. (2008). Validação de diagnósticos de enfermagem: Tipos, modelos e componentes validados [Validation of nursing diagnoses: Validated types, patterns and componentes validated]. Revista Eletrônica de Enfermagem, 10(2), 513-515. doi:10.1590/S0104-11692008000500001

Dean, C. M., Rissel, C., Sherrington, C., Sharkey, M., Cumming, R. G., Lord, S. R..... O'Rourke, S.(2012). Exercise to enhance mobility and prevent falls after stroke: The community stroke club randomized trial. Neurorehabilitation and Neural Repair, 26(9), 1046-1057. doi:10.1177/1545968312441711

Diederichs, C., Mühlenbruch, K., Lincke, H., Heuschmann, P. U., Ritter, M. A., \& Berger, K. (2011). Predictors of dependency on nursing care after stroke. Deutsches Ärzteblatt International, 108(36), 592-599. doi:10.3238/ arztebl.2011.0592

Fehring, R. (1994). The Fehring model. In R. M. Carroll-Johnson \& M. Paquette (Eds.), Classification of nursing diagnosis: Proceedings of the tenth conference (pp. 55-62). Philadelphia: J. B. Lippincott.

Galdeano, L. E., \& Rossi, L. A. (2006). Validação de conteúdo diagnóstico: critérios para seleção de expertos [Validation of diagnostic content: Criteria to select experts]. Ciência, Cuidado e Saúde, 5(1), 60-66. Retrieved from http://periodicos.uem.br/ojs/index.php/CiencCuidSaude/ article/view/5112/3327
Gurková, E., Žiaková, K., \& Cáp, J. (2011). Content validation of hopelessness in Slovakia and Czech Republic. International Journal of Nursing Terminologies and Classifications, 22(1), 33-39. doi:10.1111/j.1744-618X. 2010.01173.x

Herdman, T. H. (Ed.). (2012). NANDA International nursing diagnoses: Definitions and classification, 2012-2014. Oxford: Wiley-Blackwell.

Moorhead, S., Johnson, M., Mass, M., \& Swanson, E. (Eds.). (2012). Nursing outcomes classification (NOC) (5th ed.). St. Louis, MO: Mosby.

Moreira, R. P. (2011). Pacientes com acidente vascular cerebral: validação de definições constitutivas e operacionais construídas para o resultado de enfermagem mobilidade [Patients with stroke: Validation of constitutive and operational definitions constructed for the mobility nursing outcome]. Retrieved from Federal University of Ceará Dissertations and Theses (CDD616-81), Ceará, Brazil.

Pasquali, L. (1999). Instrumentos psicológicos: manual prático de elaboração [Psychological tools: Practical manual of elaboration]. Brasília: LabPAM/ IBAPP.

Tyson, S. F., Connell, L., Busse, M., \& Lennon, S. (2009). What do acute stroke physiotherapy do to treat postural control and mobility? An exploration of the content of therapy in the UK. Clinical Rehabilitation, 23(11), 10511055. doi:10.1177/0269215509334837

Vitor, A. F. (2010). Revisão do resultado de enfermagem comportamento de prevenção de quedas: análise do conceito e validação por especialistas [Review of the nursing outcome behavior for falls prevention: Concept analysis and validation by experts]. Retrieved from Federal University of Ceará Dissertations and Theses (CDU610-73), Ceará, Brazil. 